\title{
Evaluation of oilseed crop rotations with agro-environmental indicators
}

Oléagineux, Corps Gras, Lipides. Volume 10, Numéro 3, 198-201, Mai 2003, Colza : enjeux et nouvelles synergies de la recherche, RECHERCHE

Auteur(s) : André POUZET, Raymond REAU, Dominique WAGNER , CETIOM (France) 12, avenue George V, 75008 Paris Tel: 0156895700 - Fax: 0156895704 .

Author(s) : André POUZET, Raymond REAU, Dominique WAGNER

Summary : The European Common Agricultural Policy is shifting an increasing part of the subsidies to eco-conditionality. Henceforth, it becomes essential to evaluate the environmental effect of agricultural practices, and more generally performances of cropping and farming systems, in order to design and to develop more sustainable systems. This assessment is being implemented for the main cropping systems of some French regions, using environmental indicators. Eleven exposure indicators were chosen in order to represent a wide range of specific sustainability objectives dealing with water, soil, air, non-renewable resources, biodiversity, and landscape. The results present the sustainability assessment for the crop rotations of Champagne Berrichonne region in the Centre of France.

Keywords : Key words : sustainability, exposure indicator, rotation, oil seeds

\section{ARTICLE}

Auteur(s) : André POUZET, Raymond REAU, Dominique WAGNER

CETIOM (France) 12, avenue George V, 75008 Paris

Tel: 0156895700 - Fax: 0156895704

\section{How to evaluate the durability of rotations}

The Common Agricultural Policy and public financing for agriculture tend to answer people's expectations. However in Europe today, food sufficiency is no longer considered as a priority. Present demands towards agriculture concern much more the quality of products, life quality and the quality of landscapes and their environments. That is why the European Community started a policy of rural development [1].This led to the setting up of the 'second pillar of the Common Agricultural Policy' and an evolution toward the eco-conditionality of financial aids which represent a major stake for all production sectors and more particularly for the oilseed sector in Europe. Indeed, in a more and more open economy, producers have been incited to specialize in activities and productions where they were particularly competitive. Consequently, they had to decrease the diversity of their productions and artificialize the environment, which brings about environmental problems regularly, and also more generally durability problems. This trend has been reinforced with the introduction of 
the system of single aid/ha set up in the framework of the Agenda 2000. Nowadays, many producers prefer to specialize in cropping systems based on cereals, more than on oilseed crops.In this context, this 'second pillar of the Common Agricultural Policy' may be the instrument giving the possibility to support the non cereal sectors, if we can prove the durability performances of long-term and diversified rotations compared to short-term rotations including mainly cereals. To evaluate the present situation and think of more performing possibilities, it was urgent to develop tools to carry out these environmental evaluations. This process started with the preparation of the measure for the diversification of crops in the rotation system (called "rotation measure") in the framework of the Plan of national rural development in 2002. The first step in these arrangements was to evaluate cropping systems, their development in time and their diversity in several French areas.The setting up of this measure gave us the opportunity to carry out a first practical evaluation to compare the performance of several rotations in a given region [2]: in our example, the "Champagne Berrichonne" (table 4).

\section{The main fields of performance}

To evaluate the performance of durable development, the OECD proposed to study a whole set of impacts. We started from this multi-criteria approach and stressed out the different sets of possible impacts [3]:

- water (surface water, ground water / quality and quantity),

- the soil (quantity, structure, chemical quality, biological quality),

- the air,

- the non renewable resources,

- the biodiversity and

- the landscape.

In order to carry these evaluations, we chose the criteria which seemed to be particularly appropriate for the society as well as for producers among the whole set of available criteria. Following Halberg's and Girardin's [3, 4] proposals, these indicators were chosen due to their ability to:

- give to understand the complex reality of the impact of cultural practices on the environment and the utilization of resources,

- be valid from a scientific point of view,

- be clear and meaningful for producers,

- be sensitive to changes in cultural practices, and reflect the expected consequences, - and be easily computable with non expensive data to gather.

For example, in the field of the environment, we were led to give more importance to criteria of polluting pressure, which give a good description of the impact of practices. And we did not take into account the expensive indicators of environmental states, which are not sufficiently sensitive to modifications of practices in an isolated plot, as well as other producers' indicators which are less meaningful for the Society and offer no scientific validity to estimate the environmental impacts [5]. 
Considering the presently available methods $[6,7]$, the working group proposed eleven indicators gathered in four different fields of main impacts: the use of energy and water resources, the quality of water, soils and air, biodiversity and landscapes.

\section{The indicators of durability}

The table given below indicates the fields of impacts and the directions for computation for each indicator (tables 1, 2, 3)

Table 1. Eleven indicators of durability.

- Energizing efficiency $\bullet$ Number of phytosanitary Proportion of crops Number of crops (NB) (NRJ) treatments (PHY) winter/spring (H/P)

- Water consumption - Mass of chemical products Annual soil cover Melliferous flowering (IRR) (MAS)

(CVT) (FLO)

- Nitrogen balance (SN)

- Soil cover in autumn (CVA)

- Humic balance (MO)

Table 2. Description of the durability indicators.
Energizing efficiency Use of non renewable Energy economy Energy ratio (resource/cost) resources
Irrigation water Use of water resources
Ratio (reference local
consumption
consumption/ irrigation supply)
Number of Quality of waters
phytosanitary
Quality of the air Average number of phytosanitary
treatments applied and soils treatments applied to the plot
Mass of phytosanitary Quality of waters products
Quality of waters Total quantity of active matter and soils applied
Nitrogen balance Quality of waters Quality of the air Plot balance (supplies/exports)
(nitrates, (N2O, NH3)
eutrophication)




\begin{tabular}{|c|c|c|c|}
\hline Soil cover in autumn & $\begin{array}{l}\text { Quality of w } \\
\text { (nitrates, } \\
\text { eutrophication) }\end{array}$ & $\begin{array}{l}\text { rs Quality of } \mathrm{t} \\
\text { and soils (erc }\end{array}$ & $\begin{array}{l}\text { Period over which a crop covers } \\
\text { the soil from August to } \\
\text { September }\end{array}$ \\
\hline Humic balance & $\begin{array}{l}\text { Quality of the } \\
\text { (carbon well) }\end{array}$ & $\begin{array}{l}\text { air Quality of } \\
\text { soils }\end{array}$ & $\begin{array}{l}\text { Hénin-Dupuis } \\
\text { (humification - humus } \\
\text { mineralization) }\end{array}$ \\
\hline $\begin{array}{l}\text { Proportion of crop } \\
\text { Spring/Winter }\end{array}$ & Biodiversity & Landscapes & $\begin{array}{l}\text { Deviation compared to the local } \\
\text { optimal proportion of winter } \\
\text { crops }\end{array}$ \\
\hline Annual soil cover & Biodiversity & Landscapes & $\begin{array}{l}\text { Period over which a crop covers } \\
\text { the soil }\end{array}$ \\
\hline \multicolumn{2}{|c|}{$\begin{array}{l}\text { Number of different Landscape } \\
\text { crops }\end{array}$} & Biodiversity & $\begin{array}{l}\text { Number of different crops in the } \\
\text { rotation }\end{array}$ \\
\hline \multicolumn{2}{|c|}{$\begin{array}{l}\text { Period of melliferous Landscape } \\
\text { flowering }\end{array}$} & $\begin{array}{l}\text { Biodiversity } \\
\text { (apiculture) }\end{array}$ & $\begin{array}{l}\text { Total number of days when } \\
\text { melliferous crops are in flower in } \\
\text { the rotation }\end{array}$ \\
\hline
\end{tabular}

Table 3. Threshold-values used for each indicator.

\begin{tabular}{|c|c|c|c|}
\hline NRJ & Energizing efficiency & 3 & 7 \\
\hline IRR & $\begin{array}{l}\text { Ratio reference local \% } \\
\text { consumption /average water } \\
\text { supply/ha }\end{array}$ & & $\begin{array}{l}\text { no irrigated Note of } 5 \text { for a } \\
\text { crop } \quad \text { ratio value of } 1\end{array}$ \\
\hline PHY & $\begin{array}{l}\text { Average number of Average/year } \\
\text { treatments /year }\end{array}$ & 7,1 & 2,9 \\
\hline MAS & $\begin{array}{l}\text { Total mass of active matter } \mathrm{G} / \mathrm{ha} / \text { year } \\
\text { used as an average }\end{array}$ & 3694 & 1405 \\
\hline SN & $\begin{array}{l}\text { Nitrogen ratio } \quad \text { (input }-\mathrm{Kg} \mathrm{N} / \text { ha/year } \\
\text { output) }\end{array}$ & 100 & -50 \\
\hline CVA & $\begin{array}{l}\text { Average ratio of soil cover \% } \\
\text { from August to December }\end{array}$ & 11 & 75 \\
\hline MO & Humic balance & -60 & 439 \\
\hline
\end{tabular}




$\begin{array}{llll}\text { H/P } & \begin{array}{l}\text { Deviation compared to the } \% \\ \text { local optimal proportion of } \\ \text { winter crops }\end{array} & 66 & 0 \\ \text { CVT } \begin{array}{l}\text { Average ratio of soil \% } \\ \text { cover/year }\end{array} & 22 & 89 \\ \text { NB Number of crops in the - } \\ \text { rotation } \\ \text { FLO Number of days when Average/year } \\ \begin{array}{l}\text { melliferous crops are in } \\ \text { flower }\end{array}\end{array}$

Table 4. Marks obtained for five rotations in the region of "Champagne berrichonne".

\begin{tabular}{|c|c|c|c|c|c|c|c|c|c|c|c|}
\hline NRJ & IRR & PHY & MAS & SN & CVA & Mo & $H / P$ & CVT & NB & FLO & \\
\hline Wheat & 4,9 & 9 & 6,6 & 4,4 & 2,0 & 4,7 & 7,9 & 5,8 & 6,5 & 1,0 & 1,0 \\
\hline Rapeseed-wheat & 4,8 & 9 & 2,9 & 3,5 & 2,6 & 5,9 & 8,2 & 5,8 & 7,0 & 3,7 & 4,8 \\
\hline Rapeseed-wheat-barley & 5,2 & 9 & 3,7 & 5,2 & 2,6 & 5,6 & 7,8 & 5,8 & 6,8 & 6,3 & 4,8 \\
\hline Sunflower-wheat-barley & 5,5 & 9 & 6,1 & 6,5 & 6,5 & 4,3 & 6,5 & 8,5 & 4,7 & 6,3 & 3,8 \\
\hline $\begin{array}{l}\text { Rapeseed-wheat- } \\
\text { sunflower-wheat }\end{array}$ & 4,9 & 9 & 4,8 & 4,5 & 4,1 & 5,6 & 7,4 & 7,8 & 5,5 & 6,3 & 7,6 \\
\hline
\end{tabular}

Six of these indicators are simple and highly descriptive. They are given rather quickly from data related to agricultural practices. They are: a certain number of crops (NB), of treatments (PHY), a mass of product (MAS), or a period of flowering (FLO) or of a soil cover (CVA, CVT). The five other indicators are composite and more complex and are expressed in the terms of balance or ratio.

These indicators are based mainly on a reading of practices without taking the soils or the local weather conditions into account. In fact, only two indicators take the environment into account: the indicators IRR and MO.

Nine indicators give a raw value which cannot be directly interpreted in this form, without any reference to an objective or to a recommended value.

Only two indicators refer to a local objective (IRR and H/P). In these cases, the aim is reached with a value of 1 for the ratio IRR and a value of 0 for the deviation $H / P /$.

The values gave us the possibility to compare several rotations for a given indicator, and therefore to classify performance in a particular field. As a matter of fact, it is enough to evaluate the difference between two rotations, and then to see what is the best rotation in terms of durability. But with a 
lack of reference, they do not give us the possibility to estimate an isolated rotation, particularly for the nine indicators mentioned above: for example, what would be the performance of a rotation with an energizing efficiency of 4 ?

That is why, and also to have a general view and make the performance of a given rotation clearer in the different fields, we chose to transform these values into marks varying between 1 and 9 within a scale of increasing durability.

To compare and classify rotations, these marks allowed us to establish means on all, or some of, these indicators and to give a global definition of each rotation.

On a practical level, the value became a mark between 1 and 9 , by a simple classification, according to the relative place of the value between two references (graph 1).

Except IRR and H/P, the marks of indicators depend on chosen values from V1 to V9. They correspond to extreme values encountered in the variation of studied rotations for all 7 different areas in 2001 . Therefore it is more here a relative classification than a real estimation.

Example of rotations in a region:

This evaluation was carried out to compare rotations in the framework of an agricultural area. Each of the indicators was estimated within a region on the level of the rotation. For each studied rotation, we described the succession of crops, the management of each crop from the preceding crop to its harvest, as well as the production results obtained. Generally, we described only one crop system by rotation: we reduced the diversity of crop managements for each crop to only one typemanagement, except for winter wheat for which we modified the crop management and the results following two preceding crops (wheat/wheat, wheat following another crop).

The presented region is "Champagne berrichonne" in the middle of France, where oilseed crops are associated to winter cereals in "dry" systems (without irrigation).

We present here a system with a sample of five different rotations. The table below indicates the marks given by rotation for each indicator (scale from 1 to 9 ).

A first analysis shows that certain indicators mark clearly the difference between these five rotations. For example: the number of phytosanitary treatments, the period of melliferous flowering, the soil covers and the nitrogen balance. On the other hand, these rotations obtain similar marks when the energizing efficiency and the humic balance are concerned.

The comparison of rotations indicates that the average mark is generally better with the length and diversity of the rotation. The shortest rotations tend to be particularly handicapped by their nitrogen balance, the mass of phytosanitary products and of course the criterion of the number of crops. The long and diversified rotations tend to offer certain advantages, concerning essentially the number of phytosanitary treatments, the nitrogen balance, the period of flowering and the balanced proportion between winter and spring crops. 


\section{An analysis of the part played by oilseeds in the rotations}

A two-by-two comparison of these rotations allows us to understand better how the replacement of a crop by another crop modifies the performance of each of these indicators. The detailed study of the introduction of oilseed crops in cereal rotations gave us the possibility to identify a certain number of interesting points, but also of tricky questions.

In the field of the utilization of resources, the energizing efficiency of the agricultural production is equivalent for the rotations with winter crops with a nitrogen fertilization higher than 150 units. It improved a little with the introduction of a crop like sunflower, for which the supplies of nitrogenous fertilizers are reduced to less than 100 units.

In the field of the quality of waters (item: phytosanitary products), the introduction of sunflower in a cereal rotation gave us the possibility to reduce the number of phytosanitary treatments as well as the mass of applied active matter. Considering the present behaviour of present varieties towards their tolerance to diseases, sunflower is a crop which requires little in matter of fungicides and insecticides. Hoeing being often applied to sunflower, the use of herbicides is then reduced. But the introduction of rapeseed penalizes cereal rotations from the point of view of these indicators; in fact, even if crop diversification allows to reduce the use of pesticides on cereals, it does not compensate for additional supplies given to rapeseed. It can explained by the use of rather old herbicides used in high quantities, several applications of insecticides, great applications of anti-slug products, rather systematic applications of phytosanitary products and little developed systematic control.

In the field of the quality of waters (item: nitrogen), the introduction of sunflower allowed us to reduce the nitrogen balance of the rotation thanks to low nitrogen needs of this crop. But the short cycle period of this crop leads to an uncovered soil in the autumn between the harvest of the preceding crop and sunflower sowing. Rapeseed and its volunteer plants following harvest cover the soil over two successive autumns, play the part of nitrate trap and also give the possibility to valorize farm-fertilizers applied in the summer. But they lead to nitrogen balances in the rotation which are less favourable than sunflower. The use of intermediate crops in these rotations could improve the soil cover in autumn without modifying the nitrogen balance.

In the field of the quality of the air and of the soils, the introduction of rapeseed in a cereal rotation seems to improve the humic balance of the soil. The nitrogen storage in the soil would be reduced in rotations with sunflower. Considering the similar evolution of the indicator CVT according to the rotations, erosion risks seem to be low in rotations based on winter crops, more particularly in rotations with rapeseed. Sowing without ploughing being a characteristic of this crop most of the time, erosion risks are also decreased. But these risks are higher with the introduction of a summer crop like sunflower. As a matter of fact, this crop is penalized by its short cycle and also by its wide spacing sowing.

In the field of the biodiversity, landscapes bearing winter cereals and winter rapeseed offfer the advantage to give a crop cover which will last over the year for a long period, but which is totally absent at the end of the summer. The introduction of crops like sunflower gives a certain balance 
between summer and winter crops, as well as plots which are covered in the summertime. Rapeseed and sunflower are an important resource for bees, while contributing to the beekeeping production (indicator FLO).

In the field of the landscapes, long and diversifed rotations lead to varied rotation systems where the crops are as many variables in the landscape. Oilseeds contribute to give a nice yellow color at the time of flowering, rapeseed early in the spring, followed by sunflower early in the summer for the example of France.

\section{Discussion}

To sum up this study, 11 indicators were used. Is this number enough to deal with the main aspects of durable development ? Is it necessary considering the priority items for the concerned agricultural region ? These were inevitable questions. Thus, to start with, the number of indicators was more reduced, but with all the problems concerning the quality of waters and nitrogen, we had to have another indicator. Now for the setting up in each of the regions, the 11 indicators were not kept for the final classification of rotations. In spite of the problems linked to its utilization [8], we used the average to compare the rotations globally. But the priority was given to the 5 indicators which corresponded to the main stakes in a given region, and we carried out a weighted average to stress out the most important indicators for the durable development in the region.

We also thought of using more complex indicators, which would have been more difficult to reckon but more representative of the durability stakes. For example, to the nitrate losses in a crop system, it is clear that an indicator including the soil cover and nitrogen balance would be more performing from this point of view. But the absence of indicator for the soil cover in autumn would be difficult for other items, such as erosion or the run-off water pollution with phytosanitary products.

In order to conform to initial tender specifications, the indicators had to be easy to compute and meaningful for farmers. That is why we were led to take environmental variables (except for IRR and MO) rather rarely, and never the properties of active matter for the indicators MAS and PHY. We have then to deal with a probably reduced readability of consequences to be expected from practical changes on performance of these systems, like the scientific validity. Choosing indicators doesn't avoid compromises [9].

These indicators are often simple describers of practices, and only nine of them are not based on a reference value, which would be meaningful and valid from a scientific point of view. Therefore, we cannot evaluate an isolated rotation but can only make comparative evaluations. Lastly, these comparative evaluations offer a lack linked to their relativity: they can lead to a certain perfectionism if the rotation under study is already highly performing, and contrarily, they can lead to a certain kind of easy going.

These limits raised no major problem to define the rotational measure since the question dealt with the comparison between long and diversified rotations in comparison with monocultures with very short rotations. In order to widen the possible utilization of these indicators to estimate rotation performance, it is now desirable to improve some of them in order to help users to take their decisions. 


\section{RÉFÉRENCES}

1. Pouzet A. Systèmes de grandes cultures et environnement. Situation et perspectives d'évolution. CETIOM $2001 ; 7 \mathrm{p} ;+$ annexes.

2. Reau R, Wagner $D$, Pilorgé $E$. Première évaluation environnementale des systèmes de cultures avec oléagineux. Oleoscope, CETIOM, Paris 2002 : pp 24-26.

3. Girardin $P$, Bockstaller $C$. Les indicateurs agro-écologiques, outils pour évaluer des systèmes de culture. OCL, 4, $n^{\circ} 6,1997$ : pp 419-426.

4. Halberg N. Indicators of resource use and environmental impact for use in a decision aid for Danish livestock farmers. Agriculture, Ecosystems and Environment 1999 ; 76 : pp 17-30.

5. Lavoux T, Trocherie F, 2001. Les indicateurs agro-environnementaux en agriculture. AGPM, Commissqion technique du maïs, Paris, 15 mars 2001. 12 p.

6. Viaux Ph. Une troisième voie en grande culture. Ed. Agridécisions, Paris, 1999 : 211 p.

7. Vilain L. La méthode IDEA, indicateurs de durabilité des exploitations agriciles. Guide d'utilisation. Educagri éditions, Ministère de l'agriculture, Bergerie nationale de Rambouillet $2000: 100$ p.

8. Bockstaller C, Girardin P. Some methological issues in the construction of environmental indicators. Europena Society of Agronomy, VII congress, Cordoue. Book of proceedings, 2002 ; pp 551-552.

9. Girardin P, Bockstaller C. Indicators : tools to evaluate the environmental impacts for farming systems. Journal of sustainable agriculture $1999 ; 13(4)$ : pp 5-21.

10. Maurizi B, Verrel J-L. Des indicateurs pour des actions de maîtrise des pollutions agricoles. Ingénieries $2002 ; 30$ : pp 3-14.

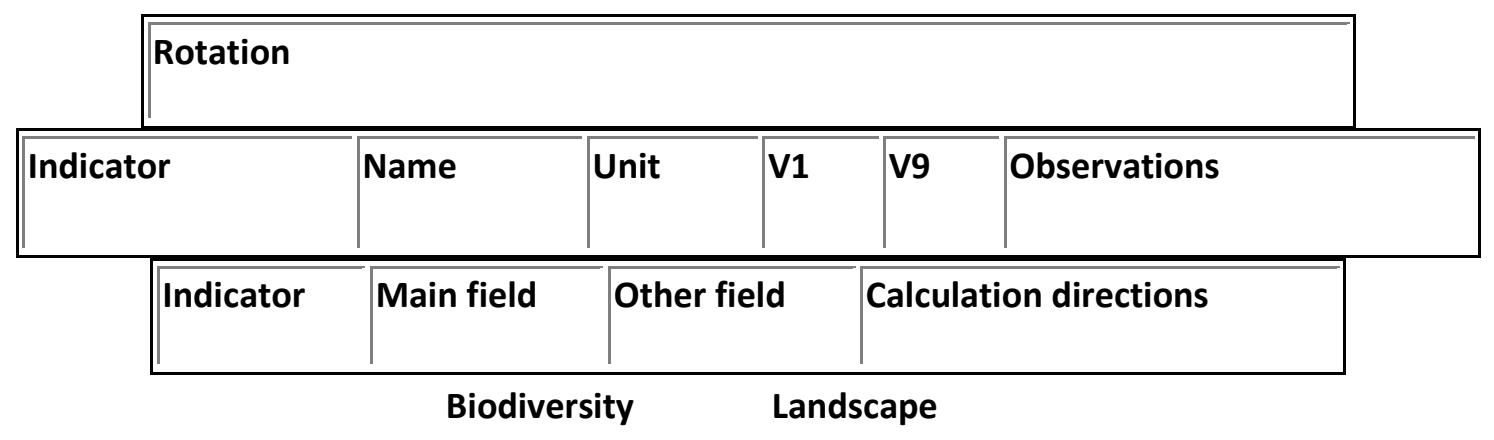

Energy and water resources Quality of waters, soils and air 


\section{Illustrations}

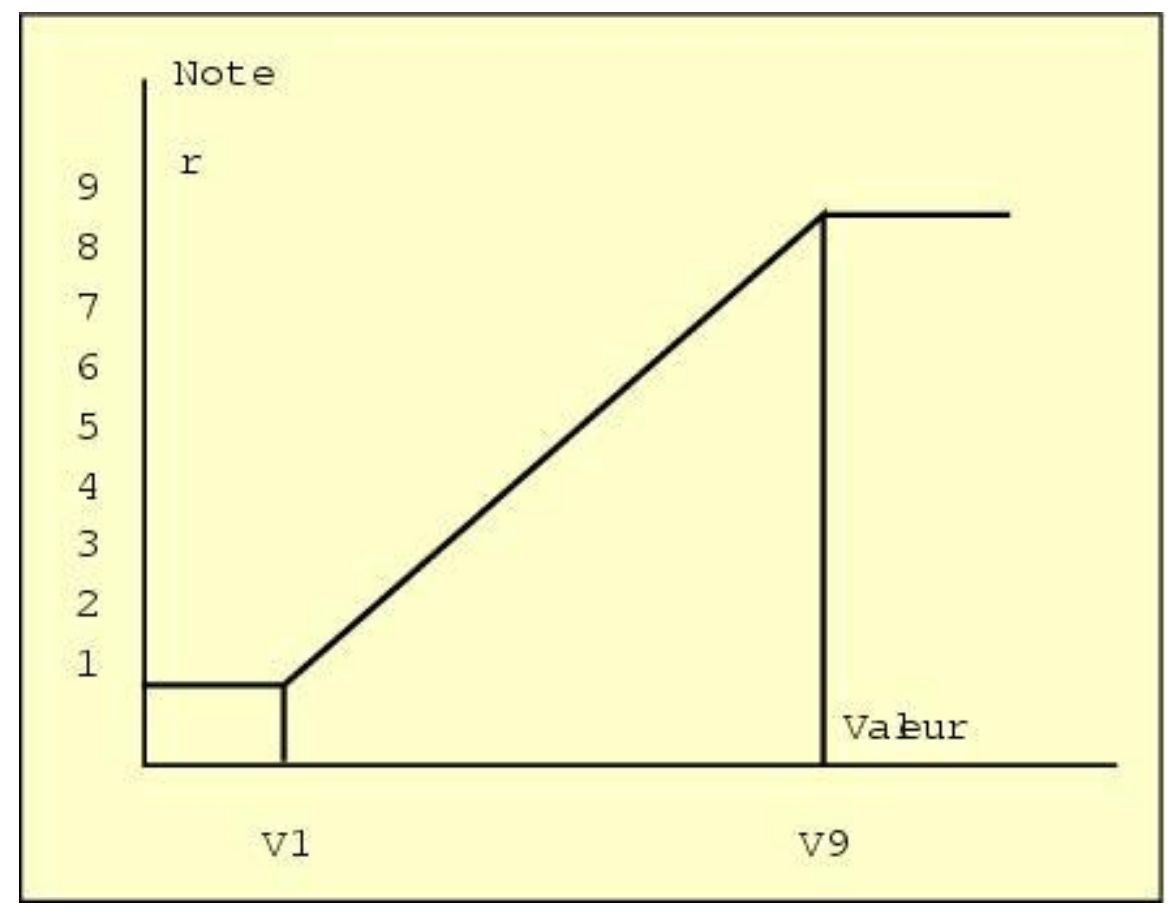

Graph. 1. Principle of value transformation into marks from 1 to 9 